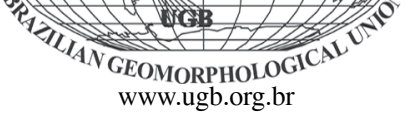

\title{
DESENVOLVIMENTO E VERIFICAÇÃO DE MÉTODOS INDIRETOS PARA A ESTIMATIVA DA ERODIBILIDADE DOS SOLOS DA BACIA EXPERIMENTAL DO ALTO RIO JARDIM - DF
}

\author{
Jorge Enoch Furquim Werneck Lima \\ Embrapa Cerrados - BR 020, km 18, CP 08223, CEP 73310-970, Planaltina, DF \\ jorge@cpac.embrapa.br
}

Euzebio Medrado da Silva

Embrapa Cerrados - BR 020, km 18, CP 08223, CEP 73310-970, Planaltina, DF euzebio@cpac.embrapa.br

Nabil Joseph Eid

Universidade de Brasília - UnB - Departamento de Eng. Civil e Ambiental - Asa Norte, CP 153041, CEP 70910-900, Brasília, DF njeid@unb.br

Éder de Souza Martins

Embrapa Cerrados - BR 020, km 18, CP 08223, CEP 73310-970, Planaltina, DF eder@cpac.embrapa.br

Sergio Koide

Universidade de Brasília - UnB - Departamento de Eng. Civil e Ambiental - Asa Norte, CEP 70910-900, Brasília, DF skoide@unb.br

Adriana Reatto

Embrapa Cerrados - BR 020, km 18, CP 08223, CEP 73310-970, Planaltina, DF reatto@cpac.embrapa.br

\begin{abstract}
Resumo
A dificuldade na determinação direta da erodibilidade (fator K) exige o desenvolvimento de métodos para estimá-la a partir de outras características dos solos de mais fácil obtenção. Entretanto, ainda não existe um método indireto considerado o melhor para a estimativa da erodibilidade do solo. O objetivo deste trabalho foi definir a melhor abordagem para se estimar a erodibilidade dos solos da bacia do alto rio Jardim - DF. Foram avaliados quatro métodos indiretos de estimativa da erodibilidade, os quais tiveram seus resultados discutidos e comparados com dados medidos. Os resultados do teste de comparação de médias tStudent indicaram que todos os métodos diferem significativamente dos dados medidos a $5 \%$ de significância. Os métodos de Denardin (1990), van der Knijff et al. (1999) e Stone \& Hillborn (2002), em média, superestimaram os valores medidos, enquanto o nomograma de Wischmeier et al. (1971) os subestimaram. De acordo com os resultados obtidos, a adoção de um valor de K por classe de solo, como normalmente utilizado, não é recomendada, pois implica em erros consideráveis. Optou-se pelo uso do método de Denardin (1990), pois foi aquele que mais se aproximou do valor medido. Com base no método de Denardin (1990) e
\end{abstract}


nos resultados de sua aplicação com os dados levantados na bacia de estudo, desenvolveu-se um novo método indireto de estimativa do valor de K, baseado unicamente no teor de argila da amostra. O método desenvolvido foi aplicado à bacia do rio Jardim de forma espacialmente interpolada e os resultados obtidos foram considerados melhores do que aqueles gerados com a adoção de um valor médio de $\mathrm{K}$ por classe de solo.

Palavras-chave: erosão, perda de solos, fator K, EUPS, bacia experimental.

\begin{abstract}
The difficulty in directly determining the soil erodibility (K-factor) stimulates the development of indirect methods to estimate it from other soil characteristics easier to determine. However, so far, there is not a universal indirect method that can be applied for estimating dependable soil erodibility values. The objective of this paper was to define the best way for estimating the Kfactor of the soils from the upper Jardim experimental river basin, located in the Federal District of Brazil. Four methods were evaluated and the results discussed and compared to measured data. The paired t-Student test at a significance level of 0.05 was used to compare the averages $\mathrm{K}$-values calculated from each tested method and none of them was found to be statistically equivalent to the measured values. The methods of Denardin (1990), van der Knijff et al. (1999), and Stone \& Hillborn (2002) overestimated the measured values, while the nomograph of Wischmeier et al. (1971) underestimated them. In spite of being a common practice, the assignment of an average erodibility value to represent each soil class demonstrated to be an important source of errors and, because of that, it should not be recommended. Among the tested methods, the Denardin's method was the one which gave better approximation to the measured K-values. Thus, considering the Denardin's method and the results of its application, using soil data from the studied basin, a new method was developed for estimating the erodibility value, based solely on the clay percentage from the soil samples. This new method was applied to the upper Jardim experimental river basin in a spatially interpolated form and the obtained results were considered better than the ones generated by using a unique erodibility value for each soil class.
\end{abstract}

Key words: erosion, soil loss, K-factor, USLE, experimental basin.

\section{Introdução}

A erodibilidade (fator $\mathrm{K}$ ) representa a facilidade com que partículas de solo são destacadas e transportadas. Segundo Bertoni \& Lombardi Neto (1995), as propriedades do solo que influenciam a sua erodibilidade são as mesmas que afetam: a velocidade de infiltração da água no solo, a permeabilidade e a capacidade de absorção de água; e aquelas que modificam a resistência à dispersão, ao salpicamento, à abrasão e às forças de transporte da enxurrada.

Bastos (1999) salienta que a erodibilidade é uma das características mais complexas de avaliação do solo em virtude do grande número de fatores físicos, químicos, biológicos e mecânicos intervenientes. No Brasil, com relação ao estudo da erosão, a erodibilidade do solo é o parâmetro de maior custo e morosidade para determinação, consequiência da extensão do território e da diversidade de solos no País (Denardin, 1990). Segundo Bastos (1999), durante muitos anos, pesquisadores de todo o mundo têm tentado relacionar a erodibilidade medida diretamente no campo com as várias características dos solos, entretanto, os dados levantados ainda são insuficientes para a quantificação adequada do potencial de erosão dos solos em função de propriedades estabelecidas em laboratório. Bastos (1999) também destaca que não existe uma metodologia indireta considerada universal para a determinação da erodibilidade do solo, o que persiste até hoje.

Segundo Silva et al. (2000), a erodibilidade do solo (fator $\mathrm{K})$ pode ser determinada de três formas. A primeira envolve a determinação do fator $\mathrm{K}$ em condições de campo, sob chuva natural, a qual é onerosa e muito demorada. O segundo método é semelhante ao primeiro, porém baseia-se na quantificação do fator K em função das perdas de solo sob condições de chuva simulada. O terceiro baseia-se em regressões múltiplas que contenham como variáveis independentes atributos do solo que podem ser correlacionados com o fator K obtido por um dos dois métodos anteriores, tidos como padrões. Existe ainda outro tipo de medida do fator $\mathrm{K}$ reportado na literatura, que é o emprego de radionuclídeos determinados no próprio solo ou sedimento, como é o caso dos isótopos de ${ }^{137} \mathrm{Cs}$ e de ${ }^{10} \mathrm{Be}$ (Zapata, 2002).

A medição direta do fator $\mathrm{K}$ de erodibilidade dos solos para a utilização da Equação Universal de Perda de Solo (EUPS) é feita por meio da instalação e operação de parcelas experimentais padrão, de elevado custo financeiro e grande 
demanda de tempo. Por causa da variabilidade do fenômeno estudado, esses experimentos devem ter duração mínima de 5 anos para a obtenção de valores representativos da média de K (Laflen, 1982). A forma empírica de obtenção de K faz com que seja necessária a calibração desses valores para diferentes solos e regiões. Em decorrência disso, há grande interesse no desenvolvimento de métodos indiretos de estimativa dessa propriedade dos solos a partir de dados de mais fácil obtenção.

Existem vários métodos propostos para a determinação indireta da erodibilidade do solo (Dumas, 1965; Wischmeier \& Mannering, 1969; Wischmeier et al., 1971; Roth et al., 1974; El-Swaify \& Dangler, 1977; Römkens et al., 1977; Denardin, 1990; Lima et al., 1990; Roloff \& Denardin, 1994; e Marques et al., 1997), cada qual com suas peculiaridades e desenvolvidos para uma dada região e/ou tipo de solo.

A carência de dados básicos e a indefinição do melhor método para a determinação da erodibilidade de maneira indireta constituem problemas a serem resolvidos (Silva \& Alvares, 2005). Silva et al. (2000) avaliaram a correlação entre os valores da erodibilidade de Latossolos brasileiros, obtidos por métodos diretos e indiretos. No caso, nenhum dos métodos testados mostrou-se adequado para a estimativa da erodibilidade para os Latossolos, sendo recomendado o desenvolvimento de modelos específicos para esses solos. Esses resultados reforçam a posição cautelosa de Cohen et al. (2005) sobre a aplicação da Equação Universal de Perda de Solos - EUPS (Wischmeier \& Smith, 1978) para a análise espacial do risco de erosão em áreas tropicais sem estudos prévios de validação com dados de campo. Esse é um fato relevante, uma vez que a EUPS é uma equação empírica, desenvolvida para condições específicas e, portanto, precisa ser calibrada antes da aplicação de seus resultados em diferentes regiões. Isso faz com que os resultados de aplicações da EUPS, muitas vezes, tenham um caráter mais qualitativo do que quantitativo, mas podem ser empregados como ferramenta de apoio à decisão para o planejamento do uso e ocupação do solo.

O objetivo deste trabalho foi definir e aplicar o melhor procedimento possível para estimar valores do fator $\mathrm{K}$ da EUPS na bacia experimental do alto rio Jardim.

\section{Material e Métodos}

Foram avaliados quatro métodos indiretos de estimativa do valor de $\mathrm{K}$, os quais tiveram os resultados discutidos e comparados com base em dados medidos nas proximidades da área de estudo. A partir da análise dos resultados alcançados e à luz de dados da literatura, buscou-se a definição de quais valores ou métodos são recomendados para a estimativa do valor de K da EUPS na bacia experimental do alto rio Jardim - DF.

\subsection{Bacia Experimental do Alto Rio Jardim}

A bacia experimental do alto rio Jardim está localizada na parte mais alta deste rio, que é afluente do rio Preto, que deságua no rio Paracatu, importante contribuinte da bacia do rio São Francisco. A área de drenagem total da bacia experimental do alto rio Jardim é de $105 \mathrm{~km}^{2}$. Localizada na parte leste do Distrito Federal (Figura 1), essa bacia

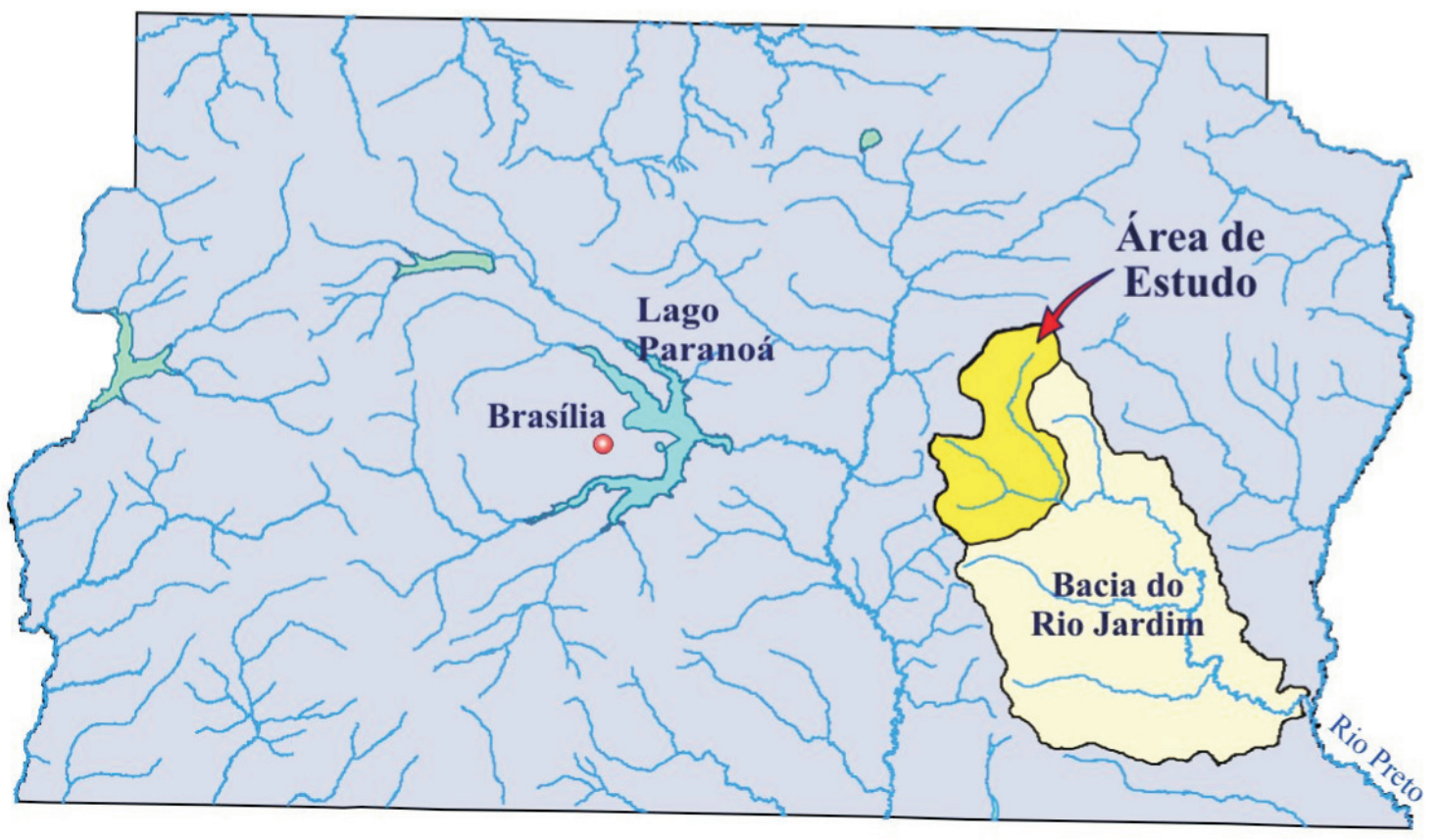

Figura 1. Mapa do Distrito Federal com a localização da área de estudo, a bacia experimental do alto rio Jardim. 
experimental está inserida na principal região agrícola dessa unidade da federação, onde se destaca o uso do solo para a produção de grãos. Além da importância em termos agrícolas e econômicos para o Distrito Federal, sua localização, central em relação ao bioma Cerrado e de fácil acesso, e suas características geoambientais (Hermuche et al., 2002; Lousada e Campos, 2005; Reatto et al., 2000) fizeram com que essa área fosse adotada pela Embrapa Cerrados como bacia experimental e representativa do bioma Cerrado.

As características climáticas da bacia são típicas da região de Cerrado, apresentando duas estações bem definidas, uma chuvosa, que se inicia entre setembro-outubro e se estende até os meses de março-abril, e outra seca, compreendendo os demais meses do ano.

Na Figura 2 é apresentado o resultado do levantamento semidetalhado dos solos da bacia experimental do alto rio Jardim (escala 1:50.000), extraído de Reatto et al. (2000), bem como os locais de coleta de amostras para a realização deste trabalho.

Com base na Figura 2, observa-se que grande parte da bacia experimental do alto rio Jardim $(76,38 \%)$ é composta por Latossolos, $16,68 \%$ é de Cambissolos e o restante é repartido entre as classes Plintossolo (2,54\%), Gleissolo (2,41\%), Neossolo Quartzarênico $(2,09 \%)$ e, ainda, uma pequena parcela de Afloramentos de Rocha $(0,24 \%)$.

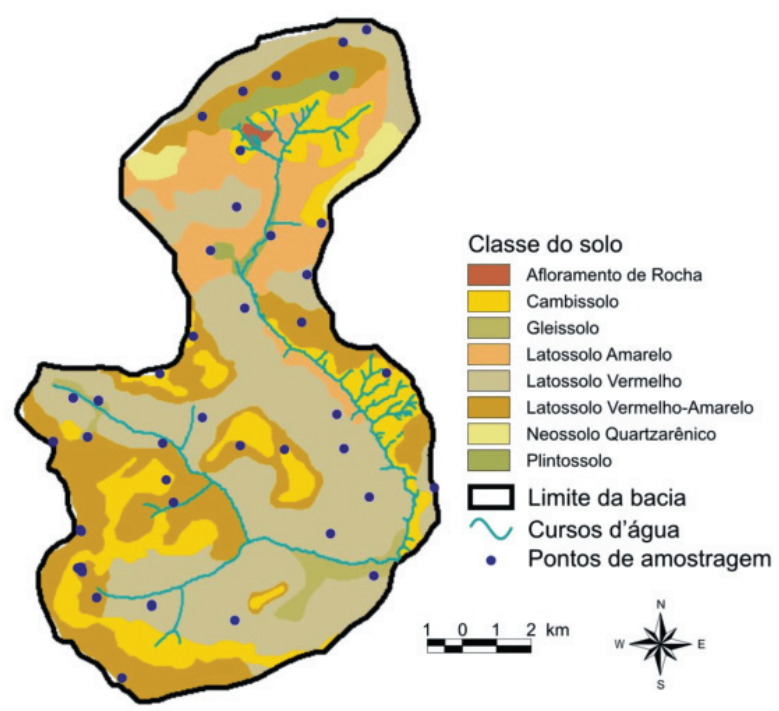

Figura 2. Mapa genérico de solos da bacia experimental do alto rio Jardim (Reatto et al., 2000) com a localização dos pontos de amostragem utilizados no presente trabalho.

\subsection{Estimativa dos Valores de $K$}

Os valores de $\mathrm{K}$ para os solos da área de estudo foram estimados utilizando os seguintes métodos: a) nomograma de Wischmeier et al. (1971); b) Denardin (1990); c) van der Knijff et al. (1999); e d) Stone \& Hillborn (2002).

\subsubsection{Nomograma de Wischmeier et al. (1971)}

Dentre os métodos existentes, o do nomograma de Wischmeier et al. (1971) é o mais utilizado (van der Knijff et al., 1999). Ele permite a estimativa do valor de K de forma gráfica, a partir de propriedades do solo (textura, percentual de matéria orgânica, estrutura e permeabilidade).

Para a conversão dos valores de $\mathrm{K}$ do nomograma do Sistema Inglês para o Sistema Internacional de Unidade (SI), deve-se multiplicar o resultado obtido por 0,1317 (Foster et al., 1981).

\subsubsection{Denardin (1990)}

Silva et al. (1994) efetuaram a comparação da erodibilidade estimada por seis métodos indiretos com o valor medido no campo em um Latossolo Vermelho e um Latossolo Vermelho-Amarelo, ambos sob Cerrado, e concluíram que os métodos indiretos não são adequados para estimar o fator $\mathrm{K}$ medido. Apesar disso, eles afirmam que o método desenvolvido por Denardin (1990) é o que apresenta os resultados menos imprecisos para Latossolos do Cerrado. $\mathrm{O}$ modelo de Denardin (1990) é descrito como:

$$
\begin{aligned}
\mathrm{K}= & \text { 0,00000748.M }+0,00448059 \cdot \mathrm{P}-0,0631175 . \mathrm{DMP}+ \\
& \text { 0,01039567.REL }
\end{aligned}
$$

sendo:

$$
\mathrm{M}=(\% \text { silte }+\% \text { areia_muito_fina }) *(100 \text { - \%argila })
$$

$\mathrm{P}=$ código da permeabilidade do solo segundo a classificação de Wischmeier et al. (1971), adimensional;

$$
\begin{aligned}
& D M P=\exp \left(\Sigma f_{i} \cdot \ln \left(\frac{d_{i}+d_{i-1}}{2}\right)\right), \mathrm{mm} ; \\
& R E L=\frac{\% M O}{\% \geq 0,1 \mathrm{~mm}} \quad, \text { adimensional }
\end{aligned}
$$
tros, $\%$

sendo:

$\mathrm{f}_{\mathrm{i}}=$ percentual correspondente ao intervalo de diâme-

$\mathrm{d}_{\mathrm{i}}=$ diâmetro superior do intervalo, $\mathrm{mm}$;

$\mathrm{d}_{\mathrm{i} 1}=$ diâmetro inferior do intervalo, mm;

$\% \mathrm{MO}=$ percentual de matéria orgânica, $\%$. 
Desenvolvimento e verificação de métodos indiretos para a estimativa da erodibilidade dos solos...

\subsubsection{Van der Knijff et al. (1999)}

Van der Knijff et al. (1999) desenvolveram um método baseado apenas em dados texturais dos solos, conforme apresentado na Tabela 1.

Tabela 1. Valores de K para solos europeus segundo o método de van der Knijff et al. (1999).

\begin{tabular}{lcc}
\hline Textura & Faixa granulométrica & $\mathrm{K}$ \\
\hline Grossa & Argila $<18 \%$ e & 0,0115 \\
& Areia $>65 \%$ & \\
& Argila $<35 \%$ e & \\
Média & Areia $>15 \%$ & 0,0311 \\
& ou & \\
& Argila $<18 \%$ e & \\
Média a Fina & Argila $<35 \%$ e & \\
& Areia $<15 \%$ & 0,0438 \\
Fina & $35 \%<$ Argila $<60 \%$ & 0,0339 \\
Muito Fina & Argila $>60 \%$ & 0,0170 \\
\hline
\end{tabular}

\subsubsection{Stone \& Hillborn (2002)}

Esses autores desenvolveram um método de estimativa de valores de $\mathrm{K}$ em função da classe textural e do teor de matéria orgânica do solo (Tabela 2).

\subsection{Dados para a Aplicação dos Métodos}

As amostras foram tomadas na camada superficial do solo e os locais de coleta são distribuídos na área de estudo conforme apresentado na Figura 2.

Os dados de textura foram obtidos por meio dos métodos de peneiramento e pipetagem (Embrapa, 1997). A condutividade hidráulica saturada (Ksat) foi determinada com permeâmetro de carga constante (Klute, 1965), em três profundidades $(0,15$ e $60 \mathrm{~cm})$, sendo efetuadas quatro repetições em cada ponto. $\mathrm{O}$ Ksat considerado neste trabalho foi o menor valor médio obtido nas três profundidades, ou seja, à camada mais restritiva ao fluxo da água no solo.

No caso dos dados de textura, para o uso do nomograma de Wischmeier et al. (1971), utilizou-se o modelo proposto por Lima \& Silva (2002) para o traçado das curvas granulométricas das amostras, das quais foram extraídos os percentuais de material nas faixas granulométricas requeridas: $\%$ silte + areia muito fina $(0,002-0,100 \mathrm{~mm})$; e \%areia $(0,100-$ $2,000 \mathrm{~mm}$ ). Isso foi necessário pois o método de obtenção dos dados no laboratório (Embrapa, 1997) adota uma divisão diferente das faixas granulométricas, sendo elas: argila $(<0,002$ $\mathrm{mm})$; silte $(0,002-0,050 \mathrm{~mm})$; areia fina $(0,050-0,200 \mathrm{~mm})$; areia grossa $(0,200-2,000 \mathrm{~mm})$.

As características das amostras, bem como a classificação dos solos na área de coleta, extraída do mapa de solos, são apresentadas na Tabela 3.

Como se pode observar na Tabela 3, das 37 amostras analisadas, 37,84\% é de Latossolo Vermelho-Amarelo, 35,14\% de Latossolo Vermelho, 5,41\% de Latossolo Amarelo, 13,51\%

Tabela 2. Valores de K em função da classe textural e do teor de matéria orgânica dos solos (adaptado de Stone \& Hillborn, 2002).

\begin{tabular}{lccc}
\hline & Média & $<2 \%$ & $>2 \%$ \\
Classe textural & & & 0,020 \\
\hline Muito Argilosa & 0,022 & 0,025 & 0,028 \\
Argilosa & 0,029 & 0,032 & 0,037 \\
Franco Argilosa & 0,040 & 0,043 & 0,034 \\
Franca & 0,040 & 0,045 & 0,005 \\
Areia Franca & 0,005 & 0,007 & 0,001 \\
Arenosa & 0,003 & 0,004 & 0,026 \\
Franco Argilo Arenosa & 0,026 & - & 0,016 \\
Franco Arenosa & 0,017 & 0,018 & 0,049 \\
Franco Siltosa & 0,050 & 0,054 & 0,034 \\
Argilo Siltosa & 0,034 & 0,036 & 0,040 \\
Franco Argilo Siltosa & 0,042 & 0,046 & \\
\hline
\end{tabular}


Lima, J.E.F.W. et al.

Tabela 3. Características das amostras de solos da bacia experimental do alto rio Jardim.

\begin{tabular}{|c|c|c|c|c|c|c|c|c|}
\hline $\mathrm{N}^{\mathrm{o}}$ & $\begin{array}{c}\text { Argila } \\
(\%)\end{array}$ & $\begin{array}{l}\text { Silte } \\
(\%)\end{array}$ & $\begin{array}{c}\text { Areia } \\
\text { Fina (\%) } \\
\end{array}$ & $\begin{array}{c}\text { Areia } \\
\text { Grossa }(\%)\end{array}$ & Textura & $\begin{array}{l}\text { MO } \\
(\%)\end{array}$ & $\begin{array}{c}\begin{array}{c}\text { Ksat } \\
(\mathrm{mm} / \mathrm{h})\end{array} \\
\end{array}$ & Classe de solo \\
\hline 1 & 61,47 & 9,67 & 24,35 & 4,51 & Muito argiloso & 2,3 & 763 & Plintossolo \\
\hline 2 & 80,17 & 11,55 & 7,08 & 1,21 & Muito argiloso & 2,9 & 171 & Cambissolo \\
\hline 3 & 71,34 & 18,12 & 8,78 & 1,76 & Muito argiloso & 2,5 & 451 & Latossolo Vermelho-Amarelo \\
\hline 4 & 39,58 & 36,41 & 11,06 & 12,95 & Franco argiloso & 1,4 & 574 & Latossolo Vermelho-Amarelo \\
\hline 5 & 56,26 & 13,95 & 22,78 & 7,01 & Argiloso & 2,5 & 287 & Latossolo Amarelo \\
\hline 6 & 67,2 & 18,01 & 8,09 & 6,70 & Muito argiloso & 2,4 & 471 & Latossolo Vermelho-Amarelo \\
\hline 7 & 15,28 & 10,49 & 70,39 & 3,85 & Franco aren oso & 1,8 & 342 & Latossolo Vermelho-Amarelo \\
\hline 8 & 74,34 & 14,18 & 10,03 & 1,46 & Muito argiloso & 2,9 & 618 & Latossolo Vermelho-Amarelo \\
\hline 9 & 64,14 & 14,48 & 18,74 & 2,64 & Muito argiloso & 2,4 & 179 & Latossolo Vermelho-Amarelo \\
\hline 10 & 64,3 & 10,12 & 20,32 & 5,26 & Muito argiloso & 2,9 & 83 & Latossolo Vermelho-Amarelo \\
\hline 11 & 65,36 & 13,26 & 19,12 & 2,25 & Muito argiloso & 2,5 & 370 & Latossolo Vermelho \\
\hline 12 & 62,79 & 8,28 & 22,89 & 6,04 & Muito argiloso & 3,2 & 87 & Latossolo Vermelho \\
\hline 13 & 69,65 & 10,28 & 15,17 & 4,91 & Muito argiloso & 3,0 & 237 & Latossolo Vermelho \\
\hline 14 & 58,32 & 18,83 & 20,9 & 1,95 & Argiloso & 3,3 & 387 & Latossolo Vermelho \\
\hline 15 & 66,36 & 11,1 & 20,25 & 2,29 & Muito argiloso & 3,6 & 632 & Latossolo Vermelho \\
\hline 16 & 72,05 & 12,51 & 11,18 & 4,26 & Muito argiloso & 2,6 & 139 & Latossolo Vermelho \\
\hline 17 & 66,85 & 18,85 & 10,73 & 3,57 & Muito argiloso & 3,2 & 215 & Latossolo Vermelho \\
\hline 18 & 63,83 & 17,26 & 17,15 & 1,76 & Muito argiloso & 3,7 & 328 & Latossolo Vermelho \\
\hline 19 & 72,2 & 10,71 & 13,65 & 3,45 & Muito argiloso & 2,3 & 338 & Latossolo Vermelho \\
\hline 20 & 64,81 & 18,22 & 14,75 & 2,23 & Muito argiloso & 2,8 & 317 & Latossolo Vermelho \\
\hline 21 & 73,32 & 13,77 & 12,22 & 0,69 & Muito argiloso & 2,7 & 410 & Latossolo Vermelho \\
\hline 22 & 56 & 15,18 & 10,83 & 18,00 & Argiloso & 3,2 & 137 & Cambissolo \\
\hline 23 & 31,05 & 39,41 & 24,33 & 5,20 & Franco argiloso & 3,6 & 431 & Cambissolo \\
\hline 24 & 58,2 & 18,05 & 20,76 & 2,99 & Argiloso & 2,4 & 361 & Cambissolo \\
\hline 25 & 63,85 & 13,42 & 15,58 & 7,14 & Muito argiloso & 3,9 & 494 & Gleissolo \\
\hline 26 & 33,05 & 17,81 & 41,26 & 7,88 & $\begin{array}{l}\text { Franco argilo } \\
\text { arenoso }\end{array}$ & 1,8 & 123 & Cambissolo \\
\hline 27 & 69,3 & 5,39 & 22,37 & 2,94 & Muito argiloso & 2,4 & 355 & Latossolo Vermelho-Amarelo \\
\hline 28 & 55,24 & 21,4 & 19,96 & 3,40 & Argiloso & 3,3 & 275 & Latossolo Vermelho-Amarelo \\
\hline 29 & 72,46 & 15,03 & 10,96 & 1,55 & Muito argiloso & 3,3 & 588 & Latossolo Vermelho-Amarelo \\
\hline 30 & 46,06 & 4,26 & 44,41 & 5,26 & Argilo aren oso & 3,4 & 30 & Latossolo Vermelho-Amarelo \\
\hline 31 & 73,26 & 10,4 & 13,49 & 2,85 & Muito argiloso & 2,3 & 49 & Latossolo Vermelho-Amarelo \\
\hline 32 & 55,88 & 4,81 & 31,25 & 8,06 & Argiloso & 2,6 & 273 & Latossolo Vermelho-Amarelo \\
\hline 33 & 79,19 & 12,42 & 7,35 & 1,04 & Muito argiloso & 2,4 & 107 & Latossolo Vermelho-Amarelo \\
\hline 34 & 66,99 & 17,42 & 12,75 & 2,84 & Muito argiloso & 2,5 & 126 & Latossolo Vermelho \\
\hline 35 & 65,77 & 14,79 & 16,66 & 2,78 & Muito argiloso & 3,5 & 506 & Latossolo Amarelo \\
\hline 36 & 45,41 & 11,73 & 35,94 & 6,92 & Argiloso & 3,3 & 8 & Plintossolo \\
\hline 37 & 39,21 & 49,82 & 7,27 & 3,71 & $\begin{array}{l}\text { Franco argilo } \\
\text { siltoso }\end{array}$ & 2,9 & 417 & Latossolo Vermelho \\
\hline
\end{tabular}

de Cambissolo, 5,41\% de Plintossolo e 2,70\% de Gleissolo. Das classes pedológicas identificadas na bacia, não foram tomadas amostras de Neossolo Quartzarênico e de áreas com Afloramentos de Rocha.

Com relação à textura, $64,86 \%$ dos solos amostrados são da classe "Muito Argilosa", 18,92\% da "Argilosa", 5,41\% da "Franco Argilosa" e 2,70\% de cada uma das classes "Franco Argilo Arenosa", "Argilo Arenosa", "Franco Argilo Siltosa" e "Franco Arenosa".

\subsection{Definição do K de Referência}

Segundo Silva et al. (1994), o índice de erodibilidade medido de um Latossolo Vermelho da região de Cerrado foi de 0,004 t.h.MJ ${ }^{-1} \cdot \mathrm{mm}^{-1}$ e o de um Latossolo Vermelho-Amarelo foi igual a 0,010 t.h.MJ-1. $\mathrm{mm}^{-1}$, valores de erodibilidade considerados "Muito Baixos" ( $\mathrm{K}<0,013$ t.h.MJ $\left.\mathrm{MJ}^{-1} \cdot \mathrm{mm}^{-1}\right)$.

Marques et al. (1997), na região de Sete Lagoas-MG, inserida no Bioma Cerrado, determinaram o valor de $\mathrm{K}$ para 
um Latossolo Vermelho de textura muito argilosa como sendo igual a 0,002 t.h.MJ'- $\cdot \mathrm{mm}^{-1}$.

Silva et al. (1997) encontraram um valor de K igual a 0,009 t.h. $\mathrm{MJ}^{-1} \cdot \mathrm{mm}^{-1}$ para um Latossolo Vermelho com textura argilosa da região de Goiânia-GO, também em área originalmente sob vegetação de Cerrado.

Silva et al. (2000) apresentaram diversos valores de erodibilidade $(\mathrm{K})$ de Latossolos brasileiros obtidos pelo método direto e observaram uma grande variação de 0,002 a 0,034 t.h. $\mathrm{MJ}^{-1} \cdot \mathrm{mm}^{-1}$. Esses resultados estão de acordo com os encontrados por El-Swaify \& Dangler (1977) para Latossolos de região tropical.

Analisando os dados apresentados, percebe-se a grande variabilidade desse parâmetro e a conseqüente dificuldade de utilização de valores de K generalizados e/ou regionalizados.

Dedecek et al. (1986), em estudo com 7 anos de duração, encontraram um valor de K igual a 0,013 t.h. $\mathrm{MJ}^{-1} \cdot \mathrm{mm}^{-1}$ para um solo atualmente classificado como Latossolo Vermelho. Esse estudo foi desenvolvido na área experimental da Embrapa Cerrados, que fica a cerca de $30 \mathrm{~km}$ da bacia hidrográfica em estudo. Destaca-se, ainda, que mais de $40 \%$ do solo da superfície da bacia experimental do alto rio Jardim também é da classe Latossolo Vermelho (Tabela 1). Por se tratar de resultado obtido em área próxima a região de estudo, com longo período de coleta e solos similares aos encontrados na bacia experimental do alto rio Jardim, esse resultado foi considerado como referência para a avaliação dos métodos utilizados.

\subsection{Seleção do método e de sua forma de aplicação}

A escolha do melhor método para estimar os valores de $\mathrm{K}$ na bacia do alto rio Jardim, foi realizada por meio da comparação estatística entre os resultados dos quatro modelos e o valor de $\mathrm{K}$ determinado no campo por Dedecek et al. (1986), o "K de referência", igual a 0,013 t.h.MJ'-1. $\mathrm{mm}^{-1}$. Buscando uma maior similaridade entre as amostras a serem utilizadas na comparação e o dado obtido por Dedecek et al. (1986), nessa etapa, utilizaram-se apenas as amostras de solo com teor de argila acima de $60 \%$, ou seja, 24 das 37 amostras.

Uma vez definido o método a ser utilizado, com o auxílio das ferramentas de cálculo e de interpolação de dados do programa ArcView 3.2, buscou-se a melhor forma de aplicação dos resultados obtidos, considerando a distribuição espacial dos valores do fator $\mathrm{K}$ na bacia experimental do alto rio Jardim em quadrículas (“Grid") de 30 em 30 metros.

\section{Resultados e Discussão}

Com base nos dados obtidos das amostras de solo coletadas na bacia experimental do alto rio Jardim (Tabela 3), os valores de $\mathrm{K}$ foram estimados por meio da aplicação dos quatro métodos propostos e os resultados são apresentados na Tabela 4.

Como forma de melhor visualizar a variação dos valores de $\mathrm{K}$ estimados para cada amostra por meio dos diferentes métodos, os resultados da Tabela 4 são apresentados graficamente na Figura 3, na qual o ordenamento das amostras ao longo do eixo $x$ foi efetuado em função do teor de argila dos solos analisados.

Na Figura 3, pode-se observar a existência de uma relação entre os valores de $\mathrm{K}$ e o teor de argila das amostras, afirmação válida para os quatro métodos utilizados. Solos com maiores teores de argila apresentaram, no caso, menores valores de K, porém, é visível o fato de que esta relação não é linear. Comparando-se visualmente os resultados dos diferentes métodos, observa-se que os valores de $\mathrm{K}$, dependendo do método utilizado, são muito diferentes. O nomograma de Wischmeier et al. (1971), por exemplo, apresentou os menores valores de $\mathrm{K}$, principalmente nas amostras com maior teor de argila. Segundo Loch \& Pocknee (1995), a estimativa da erodibilidade utilizando o nomograma é pouco confiável para solos mais agregados e argilosos, assertiva corroborada por Römkens et al. (1977), El-Swaify \& Dangler (1977) e van der Knijff et al. (1999). Loch \& Pocknee (1995) observaram que os valores de K medidos e estimados por meio do nomograma de Wischmeier et al. (1971) se aproximam para os solos com menor percentual de argila, entretanto, são bastante diferentes para solos com maior teor argila.

Outro fato observado com relação ao uso do nomograma para solos com alto teor de argila, como os Latossolos encontrados no Bioma Cerrado, é que os valores de $\mathrm{K}$ praticamente não variam em função do teor de matéria orgânica e da estrutura. Nesses casos, se utilizam faixas dos gráficos nas quais as curvas estão muito próximas, conforme exemplificado na Figura 4.

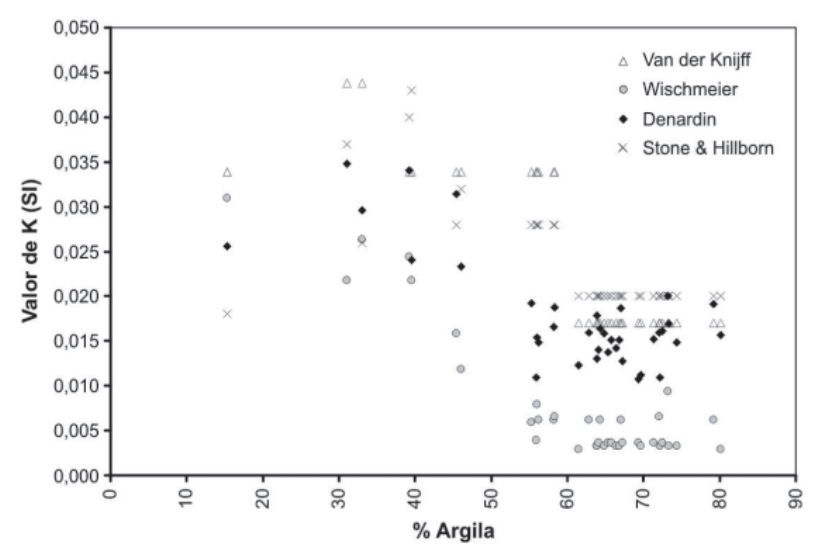

Figura 3. Valores de K estimados com os diferentes métodos e ordenados em função do teor de argila da amostra. 
Lima, J.E.F.W. et al.

Tabela 4. Estimativa do valor de K para amostras de solo da bacia experimental do alto rio Jardim.

\begin{tabular}{|c|c|c|c|c|c|c|c|c|}
\hline \multirow[b]{2}{*}{$\mathrm{N}^{0}$} & \multirow{2}{*}{$\begin{array}{l}\text { Argila } \\
(\%)\end{array}$} & \multirow{2}{*}{$\begin{array}{l}\mathrm{MO} \\
(\%)\end{array}$} & \multirow{2}{*}{$\begin{array}{l}\text { Ksat. } \\
(\mathrm{mm} / \mathrm{h})\end{array}$} & \multirow[b]{2}{*}{ Classe de solo } & \multicolumn{4}{|c|}{$\mathrm{K}\left(\mathrm{t} \cdot \mathrm{h} \cdot \mathrm{MJ}^{1} \cdot \mathrm{mm}^{-1}\right)$} \\
\hline & & & & & $\begin{array}{l}\text { Wischmeier } \\
\text { et al. }(1971)\end{array}$ & $\begin{array}{c}\text { Denardin } \\
(1990)\end{array}$ & $\begin{array}{l}\text { van der Knijff } \\
\text { et al., (1999) }\end{array}$ & $\begin{array}{c}\text { Stone \& Hillborn } \\
(2002)\end{array}$ \\
\hline 1 & 61,47 & 2,3 & 763 & Plin tossolo & 0,003 & 0,012 & 0,017 & 0,020 \\
\hline 2 & 80,17 & 2,9 & 171 & Cambissolo & 0,003 & 0,016 & 0,017 & 0,020 \\
\hline 3 & 71,34 & 2,5 & 451 & $\begin{array}{l}\text { Latossolo Vermelho- } \\
\text { Amarelo }\end{array}$ & 0,004 & 0,015 & 0,017 & 0,020 \\
\hline 4 & 39,58 & 1,4 & 574 & $\begin{array}{l}\text { Latossolo Vermelho- } \\
\text { Amarelo }\end{array}$ & 0,022 & 0,024 & 0,034 & 0,043 \\
\hline 5 & 56,26 & 2,5 & 287 & Latossolo Amarelo & 0,006 & 0,015 & 0,034 & 0,028 \\
\hline 6 & 67,20 & 2,4 & 471 & $\begin{array}{l}\text { Latossolo Vermelho- } \\
\text { Amarelo }\end{array}$ & 0,004 & 0,013 & 0,017 & 0,020 \\
\hline 7 & 15,28 & 1,8 & 342 & $\begin{array}{l}\text { Latossolo Vermelho- } \\
\text { Amarelo }\end{array}$ & 0,031 & 0,026 & 0,034 & 0,018 \\
\hline 8 & 74,34 & 2,9 & 618 & $\begin{array}{l}\text { Latossolo Vermelho- } \\
\text { Amarelo }\end{array}$ & 0,003 & 0,015 & 0,017 & 0,020 \\
\hline 9 & 64,14 & 2,4 & 179 & $\begin{array}{l}\text { Latossolo Vermelho- } \\
\text { Amarelo }\end{array}$ & 0,004 & 0,014 & 0,017 & 0,020 \\
\hline 10 & 64,3 & 2,9 & 83 & $\begin{array}{l}\text { Latossolo Vermelho- } \\
\text { Amarelo }\end{array}$ & 0,006 & 0,016 & 0,017 & 0,020 \\
\hline 11 & 65,36 & 2,5 & 370 & Latossolo Vermelho & 0,004 & 0,014 & 0,017 & 0,020 \\
\hline 12 & 62,79 & 3,2 & 87 & Latossolo Vermelho & 0,006 & 0,016 & 0,017 & 0,020 \\
\hline 13 & 69,65 & 3,0 & 237 & Latossolo Vermelho & 0,003 & 0,011 & 0,017 & 0,020 \\
\hline 14 & 58,32 & 3,3 & 387 & Latossolo Vermelho & 0,007 & 0,019 & 0,034 & 0,028 \\
\hline 15 & 66,36 & 3,6 & 632 & Latossolo Vermelho & 0,003 & 0,014 & 0,017 & 0,020 \\
\hline 16 & 72,05 & 2,6 & 139 & Latossolo Vermelho & 0,007 & 0,016 & 0,017 & 0,020 \\
\hline 17 & 66,85 & 3,2 & 215 & Latossolo Vermelho & 0,003 & 0,015 & 0,017 & 0,020 \\
\hline 18 & 63,83 & 3,7 & 328 & Latossolo Vermelho & 0,003 & 0,018 & 0,017 & 0,020 \\
\hline 19 & 72,2 & 2,3 & 338 & Latossolo Vermelho & 0,003 & 0,011 & 0,017 & 0,020 \\
\hline 20 & 64,81 & 2,8 & 317 & Latossolo Vermelho & 0,003 & 0,016 & 0,017 & 0,020 \\
\hline 21 & 73,32 & 2,7 & 410 & Latossolo Vermelho & 0,003 & 0,017 & 0,017 & 0,020 \\
\hline 22 & 56,00 & 3,2 & 137 & Cambissolo & 0,008 & 0,015 & 0,034 & 0,028 \\
\hline 23 & 31,05 & 3,6 & 431 & Cambissolo & 0,022 & 0,035 & 0,044 & 0,037 \\
\hline 24 & 58,2 & 2,4 & 361 & Cambissolo & 0,006 & 0,017 & 0,034 & 0,028 \\
\hline 25 & 63,85 & 3,9 & 494 & Gleissolo & 0,003 & 0,013 & 0,017 & 0,020 \\
\hline 26 & 33,05 & 1,8 & 123 & Cambissolo & 0,026 & 0,030 & 0,044 & 0,026 \\
\hline 27 & 69,3 & 2,4 & 355 & $\begin{array}{l}\text { Latossolo Vermelho- } \\
\text { Amarelo }\end{array}$ & 0,004 & 0,011 & 0,017 & 0,020 \\
\hline 28 & 55,24 & 3,3 & 275 & $\begin{array}{l}\text { Latossolo Vermelho- } \\
\text { Amarelo }\end{array}$ & 0,006 & 0,019 & 0,034 & 0,028 \\
\hline 29 & 72,46 & 3,3 & 588 & $\begin{array}{l}\text { Latossolo Vermelho- } \\
\text { Amarelo }\end{array}$ & 0,004 & 0,016 & 0,017 & 0,020 \\
\hline 30 & 46,06 & 3,4 & 30 & $\begin{array}{l}\text { Latossolo Vermelho- } \\
\text { Amarelo }\end{array}$ & 0,012 & 0,023 & 0,034 & 0,032 \\
\hline 31 & 73,26 & 2,3 & 49 & $\begin{array}{l}\text { Latossolo Vermelho- } \\
\text { Amarelo }\end{array}$ & 0,009 & 0,020 & 0,017 & 0,020 \\
\hline 32 & 55,88 & 2,6 & 273 & $\begin{array}{l}\text { Latossolo Vermelho- } \\
\text { Amarelo }\end{array}$ & 0,004 & 0,011 & 0,034 & 0,028 \\
\hline 33 & 79,19 & 2,4 & 107 & $\begin{array}{l}\text { Latossolo Vermelho- } \\
\text { Amarelo }\end{array}$ & 0,006 & 0,019 & 0,017 & 0,020 \\
\hline 34 & 66,99 & 2,5 & 126 & Latossolo Vermelho & 0,006 & 0,019 & 0,017 & 0,020 \\
\hline 35 & 65,77 & 3,5 & 506 & Latossolo Amarelo & 0,004 & 0,015 & 0,017 & 0,020 \\
\hline 36 & 45,41 & 3,3 & 8 & Plin tossolo & 0,016 & 0,031 & 0,034 & 0,028 \\
\hline 37 & 39,21 & 2,9 & 417 & Latossolo Vermelho & 0,024 & 0,034 & 0,034 & 0,040 \\
\hline
\end{tabular}




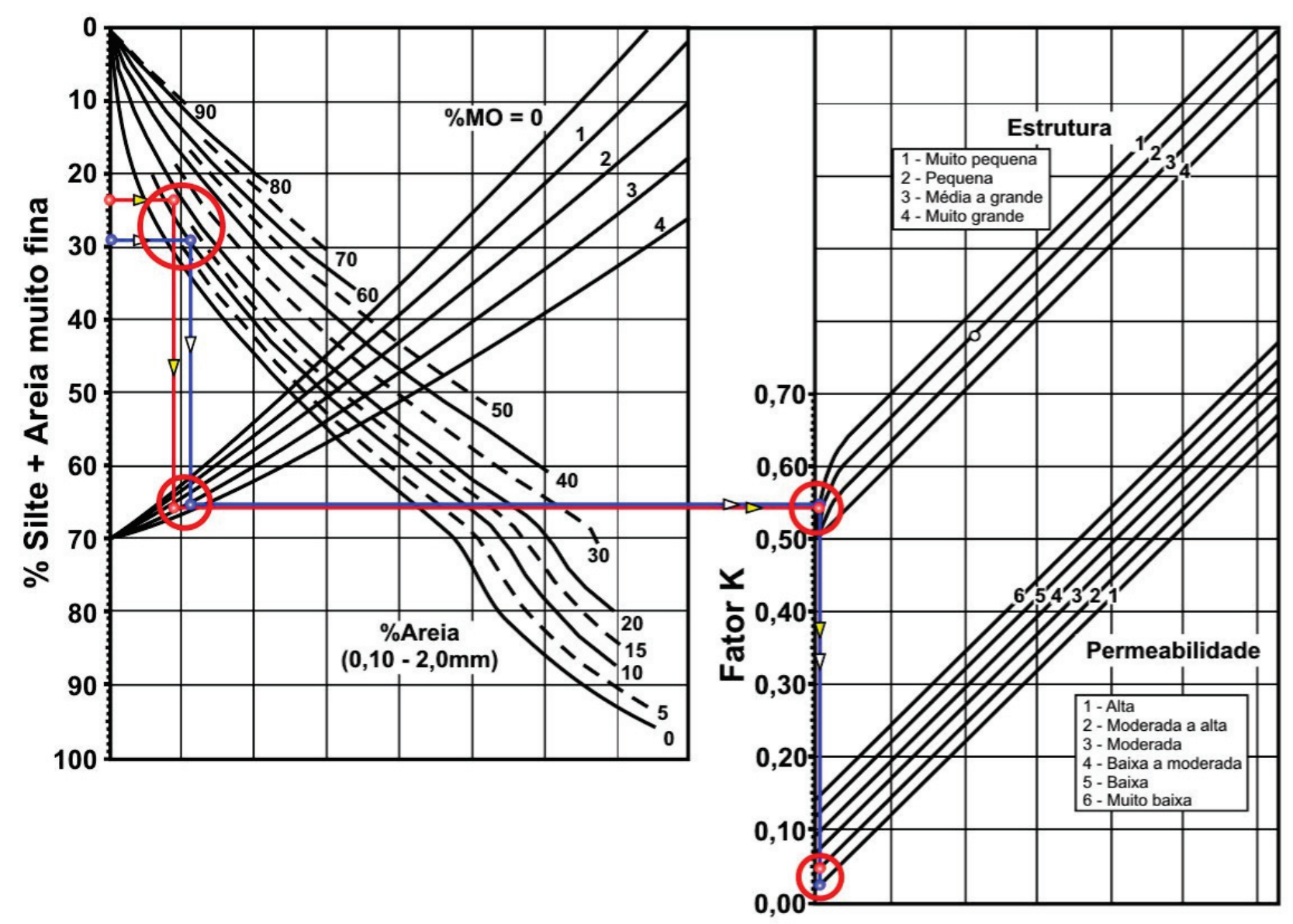

Figura 4. Exemplos de aplicação do nomograma de Wischmeier et al. (1971) para Latossolos do Bioma Cerrado.

Analisando o fato destacado na Figura 4, observa-se que a variação do valor de $\mathrm{K}$ para solos com muita argila fica dependente, quase que exclusivamente, da permeabilidade desses solos, que, no caso do Cerrado, geralmente estão inseridas nas classes "Alta" ou "Moderada a alta" do nomograma, assumindo os valores 1 ou 2 , respectivamente.

Os resultados do teste de comparação de médias tStudent indicaram que todos os métodos diferem significativamente a $5 \%$ de probabilidade do dado de Dedecek et al. (1986). Os métodos de Denardin (1990), van der Knijff $e$ t al. (1999) e Stone \& Hillborn (2002) superestimaram, na média, o valor de $\mathrm{K}$ de referência, enquanto o nomograma de Wischmeier et al. (1971) o subestimou.

Silva et al. (2000) testaram 23 diferentes métodos indiretos e concluíram que nenhum deles é recomendado para a estimativa da erodibilidade de Latossolos brasileiros, indicando a necessidade do desenvolvimento de modelos específicos para esses solos. Porém, os autores afirmaram que aquele que mais se aproximou dos resultados esperados foi o de Denardin (1990). Igualmente ao resultado de Silva et al. (2000), no presente trabalho, o método de Denardin (1990) foi aquele que mais se aproximou do valor medido por Dedecek et al. (1986). Assim, mesmo diante dos erros e incertezas apresentados, considerou-se que o método de Denardin (1990) é o mais recomendado para a estimativa dos valores de $\mathrm{K}$ para os solos da bacia do alto rio Jardim.

Uma vez assumido o método a ser utilizado, verificouse como aplicar seus resultados de forma distribuída na bacia do alto rio Jardim.

A primeira tentativa foi a de relacionar os valores de $\mathrm{K}$ às unidades de mapeamento de solo, pois, assim, seria possível espacializar os valores de $\mathrm{K}$ em função do mapa pedológico da área. Entretanto, como se pode observar na Tabela 4, para uma mesma unidade de mapeamento dos solos há diferentes valores de K. Por exemplo, para os cinco Cambissolos analisados, o $\mathrm{K}$ variou de 0,015 a 0,035 t.h.MJ ${ }^{1}$. $\mathrm{mm}^{-1}$, ou seja, um é mais que o dobro do outro. Isto também foi detectado para outras classes de solo, como nos Latossolos Vermelho-Amarelos, onde o K foi de 0,011 a 0,026 t.h. $\mathrm{MJ}^{-1} \cdot \mathrm{mm}^{-1}$. No caso dos Latossolos Vermelhos, o K variou 
de 0,011 a 0,034 t.h.MJ ${ }^{-1} \cdot \mathrm{mm}^{-1}$. Esses resultados explicitam o grande risco de erro que ocorre quando utilizado um único valor de $\mathrm{K}$ por classe de solo. Essa assertiva é corroborada por Silva et al. (2000), que observaram uma variação dos valores de $\mathrm{K}$ de Latossolos brasileiros entre 0,002 a 0,034 t.h. $\mathrm{MJ}^{-1} \cdot \mathrm{mm}^{-1}$.

A segunda alternativa consistiu em utilizar a relação detectada entre o valor de $\mathrm{K}$, determinado por meio do método de Denardin (1990), e o teor de argila do solo, conforme apresentado na Figura 5.

Observando-se a Figura 5, nota-se que o ajuste do modelo polinomial proposto para descrever a relação entre o teor de argila do solo e o valor de K foi razoável, apresentando um coeficiente de determinação igual a 0,8073. Analisando-se os erros advindos do uso da equação proposta na Figura 5, tem-se que: o erro absoluto médio do valor de $\mathrm{K}$ foi de 0,0022 t.h.MJ-1 $\mathrm{mm}^{-1}$; o erro absoluto máximo foi igual a 0,0059 t.h.MJ ${ }^{1} . \mathrm{mm}^{-1}$; o erro relativo médio foi de $12,69 \%$; e o erro relativo máximo foi de 32,16\%. Cabe destacar que esses erros são bastante aceitáveis diante da complexidade inerente à obtenção de valores de $\mathrm{K}$, e bem inferiores àqueles identificados quando utilizados um valor médio por classe de solo. Além disso, a facilidade de obtenção de dados texturais, no caso, somente do teor de argila, representa outro ponto positivo do método proposto, que constitui uma simplificação do método de Denardin (1990).

Deve-se destacar que a equação apresentada na Figura 5, proposta para simplificar a aplicação do método de Denardin (1990), só deve ser aplicada para a faixa de teor de argila das amostras utilizadas em sua concepção.
Na Figura 6, são apresentados os mapas de erodibilidade dos solos da bacia experimental do alto rio Jardim gerados das duas formas sugeridas, um com um valor de $\mathrm{K}$ por classe de solo (6.a), como utilizado por Lima et al. (2007), e o outro gerado com base no modelo proposto neste trabalho (6.b).

Como se pode observar na Figura 6, os resultados da aplicação das duas técnicas de espacialização dos valores de K na bacia, apresentadas em escalas similares, são visualmente diferentes.

No primeiro caso, Figura 6.a, onde foi aplicado um valor médio de $\mathrm{K}$ por classe de solo, a discretização dos dados é similar àquela do mapa de solos da bacia (Figura 2). Já na Figura 6.b, os valores de K seguem a distribuição espacial do teor de argila na bacia, obtida por meio da interpolação de dados medidos utilizando o método da Krigeagem. Destacase que o modelo proposto é uma equação polinomial do terceiro grau, portanto, a conversão dos teores de argila em valores de K não é linear. Deve-se ressaltar, ainda, que a estimativa da distribuição espacial de teor de argila, assim como a de outras características, é depende de uma amostragem representativa na área de estudo.

Na Figura 7 é apresentada a diferença entre os dois métodos, em termos absoluto e relativo.

Na Figura 7.a, observa-se que a diferença absoluta entre os valores de $\mathrm{K}$ determinados pelos dois métodos foi considerada "Baixa" em 39,5\% da área, "Média" em 44,7\%, "Alta" em 13,5\%, e "Muito Alta" em 2,3\% da bacia. Adiferença absoluta máxima encontrada entre os métodos foi igual a 0,022 t.h.MJ ${ }^{-1} \cdot \mathrm{mm}^{-1}$. No entanto, essa classificação para as diferenças

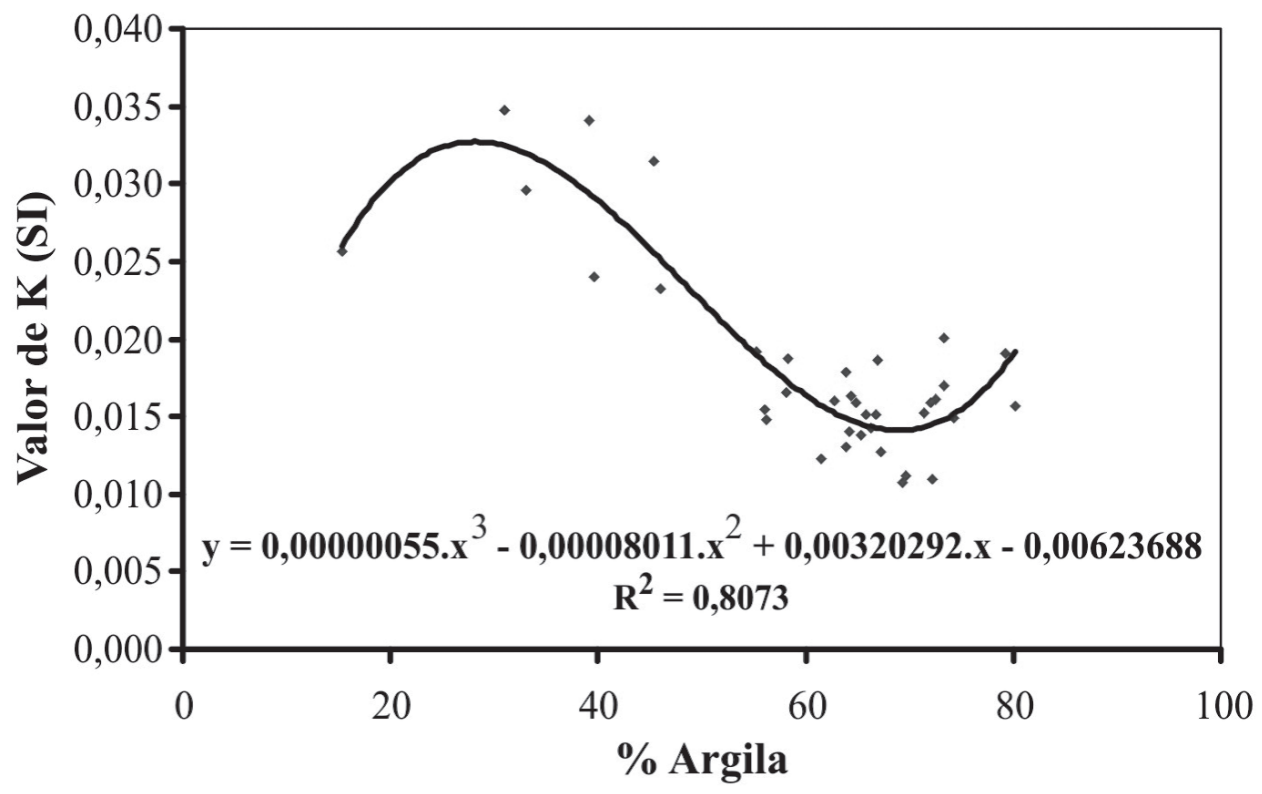

Figura 5. Relação entre o teor de argila do solo e o valor de K estimado por meio do método de Denardin (1990). 
Desenvolvimento e verificação de métodos indiretos para a estimativa da erodibilidade dos solos...
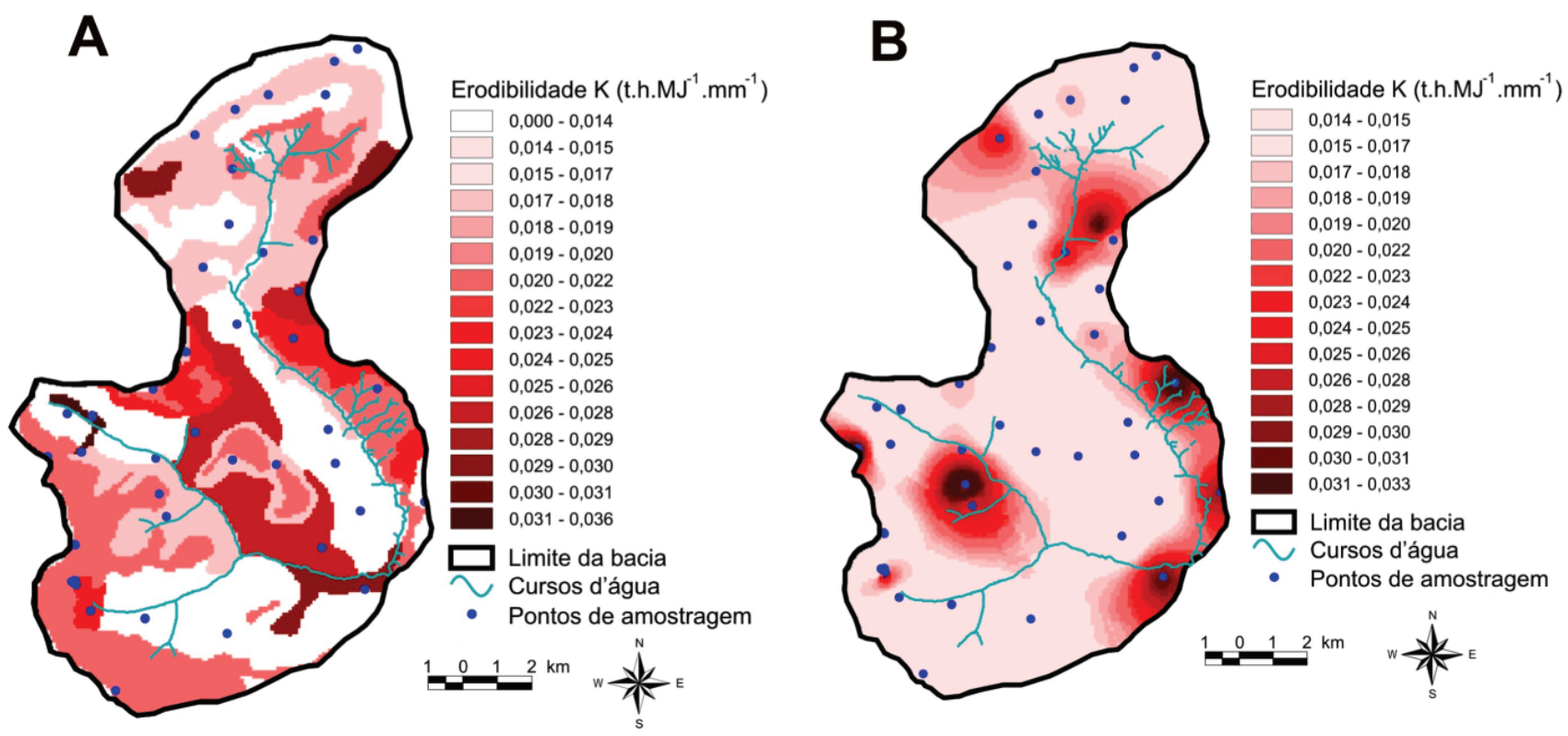

Figura 6. Mapas de erodibilidade dos solos da bacia experimental do alto rio Jardim gerados com duas diferentes técnicas: 6.a) um valor de K por unidade de mapeamento de solo; 6.b) valor de K em função da variação espacial do teor de argila dos solos.
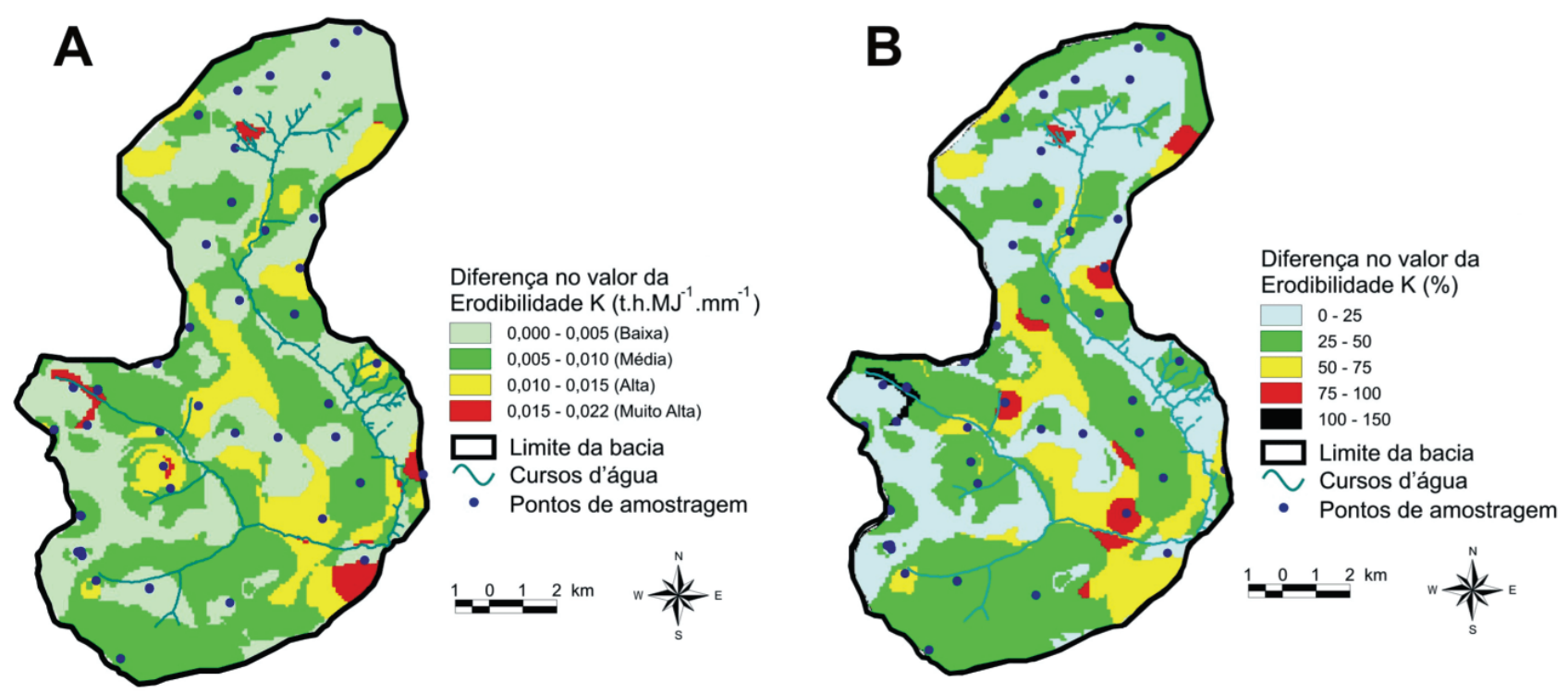

Figura 7. Distribuição espacial da diferença absoluta (a) e relativa (b) entre os métodos de obtenção de K na bacia experimental do alto rio Jardim.

absolutas é subjetiva e, por isso, na Figura 7.b, essas diferenças são apresentadas em termos percentuais, em relação aos valores obtidos com a aplicação do modelo proposto neste trabalho.

Com base nos resultados apresentados na Figura 7.b, gerou-se a curva de distribuição das diferenças percentuais entre os métodos (Figura 8).
Da análise do gráfico apresentado na Figura 8, determina-se, por exemplo, que em cerca de $80 \%$ da área da bacia a diferença entre os métodos foi inferior a $50 \%$, ou seja, em $20 \%$ da área ela foi maior que $50 \%$. Isso confirma que os resultados dos métodos têm uma diferença significativa.

Destaca-se que, em razão da Equação Universal de Perda de Solo - EUPS se tratar de um produtório de diferentes 


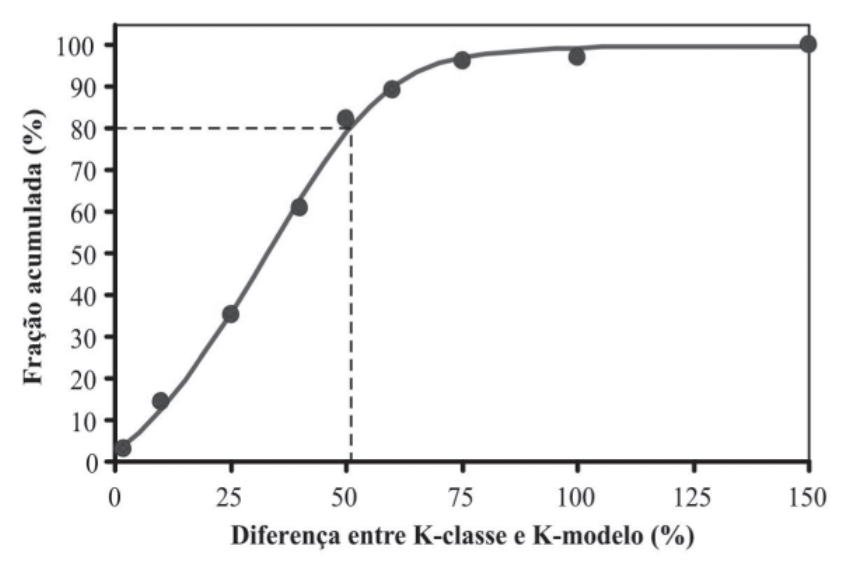

Figura 8. Curva de distribuição acumulada da diferença entre os métodos utilizados na determinação dos valores de $\mathrm{K}$ na bacia experimental do alto rio Jardim.

fatores, em que o K é um deles, uma diferença em seu valor, por exemplo, de $10 \%$, representa, de forma direta, uma diferença de $10 \%$ na estimativa da taxa de erosão da área analisada.

Diante da carência de valores de K medidos para a região; do fato de o método proposto ser baseado em dados de solos da bacia e em modelos que, apesar de empíricos, têm relação com a base física dos processos erosivos, uma vez que buscam a integração de características do solo que interferem na sua susceptibilidade à erosão; e da constatação da existência de diferença significativa entre o método proposto e a simples adoção de um valor de $\mathrm{K}$ genérico por tipo de solo, recomenda-se o uso do método indireto proposto neste trabalho para a determinação do valor de $\mathrm{K}$ na bacia experimental do alto rio Jardim.

\section{Conclusões}

1. Dentre os quatro métodos avaliados para a estimativa do valor de $\mathrm{K}$, nenhum apresentou resultado médio estatisticamente igual ao valor de $\mathrm{K}$ de referência (medido).

2. Apesar de não ter apresentado resultado médio estatisticamente igual ao valor de referência, dentre os métodos avaliados, o de Denardin (1990) é o melhor para a estimativa do valor de $\mathrm{K}$.

3. $\mathrm{O}$ uso da equação de cálculo de $\mathrm{K}$ proposta neste trabalho gera resultados diferentes daqueles obtidos por meio da adoção de um valor de $\mathrm{K}$ por unidade de mapeamento de solo.

4. Necessita-se de mais dados de K medidos diretamente na região para possibilitar o refinamento e/ou de- senvolvimento de métodos de estimativa mais confiáveis desse parâmetro da EUPS.

\section{Agradecimentos}

Aos responsáveis pelo Laboratório de Física de Solos: Wantuir Caixeta Vieira, Nelson Camargos Moreira e Lucas Cardoso da Silva; ao técnico José Roberto Leopoldino; e aos estagiários Leison Simão do Amaral, João Paulo da Conceição Bispo e Paula Andréia de Souza Alvarenga, todos da Embrapa Cerrados, pela fundamental colaboração na obtenção dos dados para a realização deste trabalho.

\section{Referências Bibliográficas}

Bastos, C.A.B. (1999) Estudo geotécnico sobre a erodibilidade de solos residuais não saturados. 256 f. Tese (Doutorado em Engenharia Civil) Universidade Federal do Rio Grande do Sul, Porto Alegre.

Bertoni, J. \& Lombardi Neto, F. (1995) Conservação do solo. São Paulo: Ed. Ícone, 356p.

Cohen, M.J.; Shepherd, K.D. \& Walsh, M.G. (2005) Empirical reformulation of the soil loss equation for erosion risk assessment in a tropical watershed. Geoderma, 124: 235-252.

Dedecek, R.A.; Resck, D.V.S. \& Freitas Júnior, E. (1986) Perdas de solo, água e nutrientes por erosão em Latossolo Vermelho-Escuro dos cerrados em diferentes cultivos sob chuva natural. Revista Brasileira de Ciência do Solo, 10 (1): 265-272.

Denardin, J.E. (1990) Erodibilidade de solo estimada por meio de parâmetros físicos e químicos. $81 \mathrm{f}$. Tese (Doutorado em Solos e Nutrição de Plantas) Escola Superior de Agricultura Luiz de Queiroz, Piracicaba.

Dumas, J. (1965) Relation entre l'érodibilité des sols et leurs caractéristiques analytiques. Cahiers Orstom Série Pédologie, Bondy, 3 (4): 307-333.

El-Swaify, S.A. \& Dangler, E.W. (1977) Erodibilities of selected tropical soils in relation to structural and hydrologic parameters. In: National Conference on Soil Erosion, 30., West Lafayette. Proceedings. Ankeny: Soil and Water Conservation Society. p. 105-110.

EMBRAPA-CNPS - Centro Nacional de Pesquisa de Solos. (1997) Manual de métodos de análise de solos. 2. ed. Rio de Janeiro: Embrapa Produção de Informação. 212 p. 
Desenvolvimento e verificação de métodos indiretos para a estimativa da erodibilidade dos solos...

Foster, G.R.; Mccool, D.K.; Renard, K.G. \& Moldenhauer, W.C. (1981) Conversion of the universal soil loss equation to SI metric units. Journal of Soil and Water Conservation, 36: 355-359.

Hermuche, P. M.; Guimarães, R. F.; Carvalho, A. P. F.; Martins, E. S.; Druck, S.; Carvalho Júnior, O. A.; Santos, N. B. F. dos \& Reatto, A. (2002) Morfometria como suporte para elaboração de mapas pedológicos: I. Bacias hidrográficas assimétricas. Planaltina, DF: Embrapa Cerrados, 25 p. (Documentos $n^{\circ} 68$ ).

Klute, A. (1965) Laboratory measurements of hydraulic conductivity of saturated soil. In. Black, C.A.; Evans, D.D.; White, J.L.; Ensminger, L.E.; Clark, F.E. (Eds.). Methods of soil analysis. I. Physical and mineralogical properties, including statistics of measurement and sampling. Madison: American Society of Agronomy. p. 210-221.

Laflen, J.M. (1982) Special problems of the USLE: Soil erodibility $(\mathrm{K})$. In: Workshop on Estimating Erosion and Sediment Yield on Rangelands, Tucson, Arizona. Proceedings. USDA, p.63-72.

Lima, J.E.F.W. \& Silva, E.M. (2002) Utilização do modelo modificado de Genuchten para o traçado da curva granulométrica. In. Encontro Nacional de Engenharia de Sedimentos. 5., São Paulo. Anais. São Paulo: Associação Brasileira de Recursos Hídricos. p.121-125.

Lima, J.M.; Curi, N.; Resende, M. \& Santana, D.P. (1990) Dispersão do material de solo em água para avaliação indireta da erodibilidade em Latossolos. Revista Brasileira de Ciência do Solo, 14 (1): 8590.

Loch, R.J. \& Pocknee, C. (1995) Effects of aggregation on soil erodibility: Australian experience. Journal of Soil and Water Conservation, 50: 504-506.

Lousada, E.O. \& Campos, J.E.G. (2005) Proposta de modelos hidrológicos conceituais aplicados aos aqüíferos da região do Distrito Federal. Revista Brasileira de Geociências, 35 (3): 407-414.

Marques, J.J.G.S.M.; Curi, N.; Ferreira, M.M.; Lima, J.M.; Silva, M.L.N. \& Sá, M.A.C. (1997) Adequação de métodos indiretos para estimativa da erodibilidade de solos com horizonte B textural no Brasil. Revista Brasileira de Ciência do Solo, 21 (3): 447-456.

Reatto, A.; Correia, J.R.; Spera, S.T.; Chagas, C.S.; Martins, E.S.; Andahur, J.P.; Godoy, M.J.S. \& Assad, M.L.C.L. (2000) Levantamento semidetalhado dos solos da bacia do rio Jardim - DF, escala 1:50.000. Planaltina: Embrapa Cerrados. 63p. CD ROM (Boletim de pesquisa $\mathrm{n}^{\circ} 18$ ).
Roloff, G. \& Denardin, J.E. (1994) Estimativa simplificada da erodibilidade do solo. In. Reunião Brasileira de Manejo e Conservação do Solo e da Água, Florianópolis. 10., Anais. Florianópolis: Sociedade Brasileira de Ciência do Solo. p.150-151.

Römkens, M.J.M.; Roth, C.B. \& Nelson, D.W. (1977) Erodibility of selected clay subsoils in relation to physical and chemical properties. Soil Science Society of America Journal, 41 (5): 954-960.

Roth, C.B.; Nelson, D.W. \& Römkens, M.J.M. (1974) Prediction of subsoil erodibility using chemical, mineralogical and physical parameters. Washington: United States Environmental Protection Agency. 111p. Report.

Silva, A.M. \& Alvares, C.A. (2005) Levantamento de informações e estruturação de um banco de dados sobre a erodibilidade de classes de solos no Estado de São Paulo. Geociências, 24 (1): 33-42.

Silva, M.L.N.; Curi, N.; Oliveira, M.S.; Ferreira, M.M. \& Lombardi Neto, F. (1994) Comparação de métodos diretos e indiretos para determinação da erodibilidade em Latossolos sob Cerrado. Pesquisa Agropecuária Brasileira, 29 (11): 17511761.

Silva, M.L.N.; Freitas, P.L.; Blancaneuax, P.; Curi, N. \& Lima, J.M. (1997) Relação entre parâmetros da chuva e perdas de solo e determinação da erodibilidade de um Latossolo Vermelho-Escuro em Goiânia (GO). Revista Brasileira de Ciência do Solo, 21 (1): 131137.

Silva, M.L.N; Curi, N.; Lima, J.M. \& Ferreira, M.M. (2000) Avaliação de métodos indiretos de determinação da erodibilidade de Latossolos brasileiros. Pesquisa Agropecuária Brasileira, 35 (6): $1207-$ 1220.

Stone, R.P. \& Hillborn, D. (2002) Universal Soil Loss Equation (USLE). Canadá: Ontário Ministry of Agriculture and Food (OMAFRA). ISSN: 1198-712X. http:// www.gov.on.ca/OMAFRA/english/engineer/ facts/00-001.htm

Van Der Knijff, J.M.; Jones, R.J.A. \& Montanarella, L. (1999) Soil erosion risk assessment in Italy. European Soil Bureau. Joint Research Center of the European Commission, 52 p. Report.

Wischmeier, W.H.; Johnson, C.B. \& Cross, B.V. (1971) A soil erodibility nomograph for farmland and construction sites. Journal of Soil and Water Conservation, 26 (5): 189-193. 
Wischmeier, W.H. \& Mannering, J.V. (1969) Relation of soil properties to its erodibility. Soil Science Society of America Journal, 33 (1): 131-137.

Wischmeier, W.H. \& Smith, D.D. (1978) Predicting rainfall erosion losses - a guide for conservation planning. U.S. Department of Agriculture, Agriculture Handbook 537. 58 p.
Zapata, F. (Ed.). (2002) Handbook for the Assessment of Soil Erosion and Sedimentation Using Environmental Radionuclides. Holanda: Kluwer Ac. Publ. 217 p. 